\title{
LITERATURE REVIEW: PSYCHIATRY IN PATIENTS WITH BREAST CANCER
}

Ana Carolina L. Maya', Isabella C. Matos'1, Isadora C. Matos', Áurea G. Pidde'1, Isabel S. Migliavacca', Emanuel F. S. Xavier ${ }^{1}$, Luiza S. Coutinho²

${ }^{1}$ Centro Universitário de Anápolis - UniEVANGÉLICA - Anápolis (GO), Brazil.

²Pontifícia Universidade Católica do Goiás - Goiânia (GO), Brazil.

Objectives: the study aimed to connect the psychiatry of breast cancer and psychosocial aspects. Methodology: bibliographical research was conducted through LILACS and SciELO databases with the keywords breast cancer and psychiatry. Scientific articles between the period from 2006 to 2015 contemplating the subject review were selected. Results: breast cancer is the most common cancer among women in Brazil and in the world. According to INCA, in 2018, it was estimated the detection of 59,700 new cases. Besides the high prevalence and mortality, breast cancer and its treatment leads to psychosocial and social impacts on the lives of women. The psychological and physical changes caused by breast cancer justifies the wide prevalence of depression and anxiety. Mastectomy can be seen as something traumatic and even as a mutilation. Women undergoing mastectomy without breast reconstruction have higher rates of body image dissatisfaction. According to Almeida et al. (2012), satisfaction with the aesthetic result of the reconstruction concerns not just rebuilding the body, but the way each woman perceives and deals with your self-image. It is noted that psychosocial dynamics of breast surgery does not finish with the end of the treatment, as it requires long-term care. The patient's diagnosis and treatment of breast cancer is a multidisciplinary task, however the psychiatrist rarely comes into play at the beginning of the approach. The difficulty in recognizing mental frames is worrying and diagnosis is rarely done. Conclusion: It is concluded that the treatment of breast cancer raises psychosocial health effects related to dissatisfaction with their own body image. Thus, it causes anxiety and depression psychiatric frames that are underdiagnosed, since rarely the psychiatrist or psychologist are part of the multidisciplinary team. 